\title{
Addressing linguistic diversity in the European Union : strategies and dilemmas
}

\section{Kraus, Peter A.}

2014-08

pÿKraus , P A \& Kazlauskait-Gürbüz , R 2014 , ' Addressing linguistic diversity in the European Union : strategies and dilemmas ' , Ethnicities , vol. 14 , no. 4 , pp. 517-538 . https://doi.org/10.1177/14687

http://hdl.handle.net/10138/233226

https://doi.org/10.1177/1468796814528693

acceptedVersion

Downloaded from Helda, University of Helsinki institutional repository.

This is an electronic reprint of the original article.

This reprint may differ from the original in pagination and typographic detail.

Please cite the original version. 
Peter A. Kraus and Rūta Kazlauskaitè-Gürbüz, Addressing linguistic diversity in the European Union: strategies and dilemmas, Ethnicities, 14(4), pp. 517-538.

This is an Author's Accepted Manuscript. The Publisher's version of the article is available online behind this link: https:// doi.org/10.1177/1468796814528693

\section{Peter A. Kraus, University of Augsburg \\ Rūta Kazlauskaitè-Gürbüz, University of Helsinki}

\section{Addressing linguistic diversity in the European Union: strategies and dilemmas ${ }^{1}$}

\section{Keywords}

European integration, European Union, identity politics, language policy, language politics, linguistic diversity, multilingualism

\footnotetext{
Abstract

In multilingual environments, respecting diverse linguistic identities is a requirement for recognizing the equal dignity of citizens. In the official discourse of the European Union, the approach to linguistic diversity has typically oscillated between two normative poles. On the one hand, linguistic diversity is seen as a central element of Europe's cultural inheritance, as an asset that is a pillar for achieving the intercultural understanding on which a trans-European civil society has to rely. On the other hand, multilingualism is seen as a challenge for creating an integrated market-cum-polity. The way to confront this challenge consists in turning it into a potential economic asset: multilingualism thereby becomes primarily a competitive advantage in a global context characterized by cognitive mobility in knowledge-based societies. In its attempt at delineating a strategy between these two poles, European language policy entails multiple contradictions. Ultimately, it may be associated with an embrace of multilingualism in which the value of linguistic diversity is reduced to economic criteria. Due to the lack of proper political foundations for coping with linguistic diversity at the European level, we are facing an impasse in which the recognition of equal dignity is put at risk by a normatively inconsistent marketing of diversity.
} 


\section{Introduction: European diversity as linguistic diversity}

Virtually all declarations of principles passed in the name of Europe over the last decades stress the importance of protecting cultural diversity. Again and again, the European Union (EU) has kept reassuring its Member States and its citizens that, regardless of all political common ground that may emerge among Europeans, the European project does not involve any measures making for uniform patterns of cultural identification (Kraus, 2011: 24-25). On the one hand, this celebration of diversity, especially when set against the background of nation-state formation, can be regarded as one of the most genuine new contributions European integration has thus far made to the language of contemporary constitutionalism (Weiler, 1999). At the same time, the recurrent official statements stressing the importance of diversity as a European value do not produce a programmatic frame that would provide us with a set of consistent guidelines fleshing out political criteria for the protection of diversity in the realms of society which are most openly exposed to the standardizing pressures connected with European integration. Rather, one can argue that the emphasis placed on respecting cultural diversity must be seen, first and foremost, as a tribute the Union pays to its key units - i.e. the European nation-states - in order to make them comply with the institutional implications of the process of building Europe.

Linguistic diversity figures among the most salient manifestations of cultural diversity in presentday Europe. Compared with other areas of what has come to be considered the modern West, such as North America, Europe forms a patchwork of different languages, many of which are closely interwoven with particular political identities. Accordingly, the realm of language offers an excellent opportunity for scrutinizing the effective consequences of the integration-cum-diversity discourse. Before giving an overview of European policies that tackle the language issue, this contribution outlines a normatively and sociologically grounded approach to grasping the political implications of linguistic diversity, and argues that, in a multilingual environment, respecting diverse linguistic identities is a requirement for recognizing the equal dignity of citizens. Against this background, key policy documents that exemplify how the EU tackles issues of multilingualism are discussed. The Union's take on language policy has typically oscillated between two normative poles. On the one hand, linguistic diversity is seen as a pillar of Europe's cultural inheritance, as an asset that is of paramount importance when it comes to achieving the intercultural understanding on which a trans-European civil society has to rely. On the other hand, multilingualism is primarily regarded as an economic asset and thereby becomes a potential competitive advantage in a global 
context characterized by cognitive mobility. As will be argued in the next section, in complex societies the tension between the two poles may turn out to be ultimately irreducible. It is thus not too surprising that it translates into multiple contradictions in Europe's approach to linguistic diversity. The problem rather is that the dominant element in this approach seems to be working in favor of a version of multilingualism that reduces the value of linguistic diversity to economic criteria. In our view, the tension between language as an 'identity marker' and language as a 'strategic device' in multilingual Europe can hardly be overcome; yet this does not necessarily imply that it cannot be dealt with according to politically defined criteria that aim at finding a fair balance between protecting diversity and facilitating integration in the transnational and multilingual civic constituted by European citizens. If our argumentation holds, the very lack of a proper political framework for coping with linguistic diversity at the European level is the main cause of an impasse in which the recognition of equal dignity is put at risk by a marketing of diversity that lacks normative consistency.

\section{Outlining a grounded approach to linguistic diversity}

Current debates on the value of linguistic diversity often start from the matter-of-fact observation that about one third of the 6000 languages which are spoken in the world at present must be considered as endangered. Linguists tend to interpret the death of a language as a catastrophe. In their opinion, those who belong to a language community experience the disappearing of their language as a 'traumatic event'. ${ }^{2}$ The trauma of language death will become a recurrent experience through the $21^{\text {st }}$ century, as the waning of linguistic diversity at the global level - measured as the decrease of the absolute number of living languages - seems to be an unstoppable trend. Major efforts are being made in the scientific realm to compensate for this trend by gathering sufficient information on languages that are dying, so that they can be codified for forthcoming generations.

At the same time, losing 'one's' vernacular is hardly synonymous with becoming speechless. Even if language $\mathrm{X}$ is not passed from one generation to the next, those who belong to different generations - parents and children - keep communicating with each other, although in another language than that employed when the parents talked to their children's grandparents. Thus, the process parallel to language death is language substitution, a process by which the speakers of language $\mathrm{X}$ switch individually and collectively to a language $\mathrm{Y}$. Such a dynamic we find frequently in the context of migration: the grandchildren of, say, Polish or Italian immigrants to the 
US have lost their ancestors' native tongues, even if they keep labeling themselves Polish or Italian Americans. Language substitution is also a typical outcome in situations where contact between distinct language communities entails the subordination of a 'low-standard' vernacular vis-à-vis a 'higher' language.

Ultimately, the question of language death and, by extension, of language rights that should contribute to avoiding the corresponding dynamic cannot be detached from the question of human rights: languages are not subjects; their speakers are. Obviously, those who suffer when a language disappears are not the languages as such, but the members of communities who share a particular language. The qualification should be uncontroversial, yet it still leaves significant potential for contrasting views on what is effectively lost in the process of language substitution. Let me substantiate the point with three examples.

(1) In their celebrated film Padre Padrone, produced in 1975, the Taviani brothers describe the oppressive patriarchal setting to which the young shepherd Gavino Ledda is exposed in the countryside of Sardinia. For Gavino, learning and beginning to use Italian as his main language is a decisive part of emancipating himself from this setting, and thus a condition of achieving cognitive freedom.

(2) In a private conversation, a Finnish colleague, an authority in the field of intellectual history, had no reservations in characterizing Finnish as a 'prison'. The image was used to convey that, to get a broader view of the world, members of Finnish academia needed to be trained in the languages of larger communities of knowledge, that is English, in the first place, and to a minor extent perhaps German or French. Otherwise, they would remain trapped in intellectual parochialism.

(3) The perspective of the Finn stands in stark contrast with the position of a Basque colleague, who works at a university in the Spanish part of the Basque Country and whose main field is the philosophy of science: he sees one of the key challenges of his professional activity in expanding the use of the vernacular to the higher domains of scientific communication. His ambition lies in teaching analytical philosophy and epistemology in Basque. From his perspective, using the language at home, with his partner and children, reading Basque literature, and having the daily news broadcast in Basque is important, but not sufficient for overcoming the subordinate standing of the vernacular language in its historical environment. 
As these examples show, the commitment that members of a language community exhibit towards 'their' language varies heavily with contextual factors. In the first two cases, speakers of so-called 'smaller' languages seem eager to embrace alternative linguistic affiliations, which allow for more extensive communicative experiences. It has to be noted that the attitude of the Finnish scholar emerges from a situation that reflects the long-term success of linguistic nationalism, which has given Finnish a secure status as standard language used in all domains of society. ${ }^{3}$ In the case of the Basque philosopher, the approach follows a completely different logic: here, language is seen as a substantial component of a socio-cultural setting in which we must be able to feel 'completely' at home in our day-to-day interaction, be it by teaching Thomas Kuhn's insights in Basque or by sharing our primary communicative code with the bulk of the nation.

When we think about the 'value' of linguistic diversity, and of why it is an important matter for many people to have their language transmitted to coming generations, we have to be aware of the varying attitudes towards language that lie behind such examples. On the one hand, language may be experienced as something that belongs to us in a unique way, as an asset that establishes an immediate link between our life-world and the differentiated institutional realms of modern society. On the other hand, the asset may create barriers and limit our communicative practice to a comparatively narrow set of possible experiences. A language can be a gate to a universal koiné, to a virtually unbound community of speakers. This is the aspect emphasized in the first two examples, where switching from Sardinian or Finnish to, respectively, Italian or English involves a substantial expansion of exchange and learning opportunities. In the third example, in contrast, the main focus is on the significance that a particular language - Basque - bears as a tie between an individual and the bounded realm of institutionalized collective practices in which the life of this individual is embedded.

To speak of language as a gate and of language as a tie opens up interesting possibilities to relate the debate on linguistic diversity to a conceptual distinction introduced three decades ago by Ralf Dahrendorf, namely the distinction of options and ligatures, to which Dahrendorf (1979: 30) attributes critical importance in his approach to social and political theory: 'Options are possibilities of choice'; they provide us with 'structural opportunities for choice', thereby offering a template for our individual choices and decisions. Ligatures, in contrast 'are allegiances; one might call them bonds or linkages as well'. Dahrendorf (1979: 31) goes on elaborating: 'Perhaps it could be said that as choices are the subjective side of options, so linkages, or bonds, are that of ligatures.' And: 'Ligatures create bonds and thus the foundations of action; options require choices and are thus 
open for the future.' For Dahrendorf (1979: 30), the crucial significance of options and ligatures is that they are the constitutive element of the 'life chances' individuals have in contemporary societies. To realize our human potential, we might say, we depend on such life chances, which have to be understood as a function of the relations between options and ligatures. Dahrendorf (1979: 31) stresses this relational aspect, as focusing exclusively on only one of the two elements would give us a heavily distorted picture of social reality: 'A maximum of options is not by itself a maximum of life chances, nor is a minimum of options the only minimum of life chances. Ligatures without options are oppressive, whereas options without bonds are meaningless.' At the same time, it must be noted that there is not necessarily a zero-sum relationship between options and ligatures (Dahrendorf, 1979: 33): our options may increase, without that we lose our ligatures, and vice versa.

As Dahrendorf (1979: 31) acknowledges himself, conceptualizing life chances in terms of a mix of options and ligatures is not advocating a radically new approach to social and political theory, but may rather be seen as a variation of an old motive in sociological analysis, a motive which is already fully present in the work of Durkheim, Tönnies and Weber. The dynamic of modernization has often been associated with an extension of choices that simultaneously implies an erosion of bonds. What does the conceptualization now offer us when it comes to discussing linguistic diversity?

In the light of our examples, it seems clear that a strong commitment to protecting linguistic diversity will go hand in hand with an emphasis on the importance of language as a social tie, as a ligature. From this perspective, the 'value' of Finnish, Basque, and of the thousands of other 'smaller' languages resides in their representing a grid of historically and culturally mediated collective experiences on which individuals can rely when they interpret the world and make meaningful choices. A decline of linguistic diversity thus signals a loss of ligatures for those who belong to communities whose languages are fading. In the worst cases, such loss is not even compensated for by an increase of options: while communal bonds are eroded, the benefits of modernity remain absent. The situation of indigenous groups being forced to assimilate into the structures of majority societies keeps offering us perturbing evidence in this respect. Typically, members of such collectivities are uprooted, without having a proper chance for working out an approach towards the dominant culture on their own terms. ${ }^{4}$ This is the darker side of the story told in Padre Padrone, whose main character experiences cutting off ligatures as liberation. Often enough, however, progress does not deliver what it promised, leaving people in a state of anomie, 
with crumbling linkages and without choices. If the realization of our potential as human beings is contingent upon the availability of an effective combination of options and ligatures, linguistic diversity has a key role to play in the reproduction of those patterns of identification that create meaningful ties between us and our social environment.

Ultimately, the affirmation of such ties tends to become, both at the individual and at the collective level, a question of dignity: the Basque philosopher does not justify the use of Basque in academic teaching as a strategy for better accommodating his students; nor does he believe that by recurring to his native tongue he offers a perspective on his subject that could not be given in other languages. In terms of the reproduction and acquisition of sheer scientific knowledge, it seems secondary whether quantum physics at a Basque university are taught in English, Spanish or Basque. As it can safely be assumed that the vast majority of publications in this field are nowadays in English, why should Basque be used in class at all? The only plausible answer is that, in the given historical and political moment, there are Basque scholars, linked to Basque society, who feel that it is a question of their professional dignity to be able to operate at work in similar ways as their Spanish or French colleagues do, thereby offering instruction on epistemology and quantum physics in the local vernacular. In contrast, the dignity aspect apparently has become secondary for the Finnish academic, who feels comfortable enough to switch to an 'external' linguistic code when acting as a historian. For the Finn, the wish to become immersed in an unbound sphere of intellectual communication trumps criteria of linguistic proximity, which otherwise continue to apply, as Finnish remains the language of most of her activities.

Beyond individual predispositions, the differences in the two cases may ultimately reflect more general contextual variations: while Finnish has been successfully established as an official state language, and can today be considered a firmly consolidated feature of Finnish society at all levels, the sociolinguistic situation of Basque continues to be relatively precarious. At the same time, however, the two examples also indicate that the relationship between language-as-a-gate and language-as-a-tie has a complementary and variable character, as the relationship between options and ligatures has as well. Thus, that the Basque has decided to push for the presence of the vernacular in the domain of 'high' communication does not mean that he would have a problem with referring to scientific literature produced in English or, for that matter, Spanish. In the case of the Finn, the enthusiasm for the articulation of an academic community around a common lingua franca might ultimately well be qualified by the awareness of the crucial importance that a thorough 
knowledge of vernaculars has for the study of all possible areas in the humanities and social sciences.

That linguistic identities have a complementary and malleable character is a reflection of our capability to develop a multilingual repertoire. In fact, this very aspect sets language clearly apart from another politically salient marker of cultural diversity, which is religion. Contemporary societies are all characterized by a more or less high degree of religious pluralism. A significant number of European states attribute an official or semi-official status to more than one religious denomination. Yet, in this field, regardless of all efforts at tolerance and ecumenism, the additive or complementary effect which can be found in the institutional domain is obviously not transferable to the level of individuals: our Finnish historian may write the bulk of her publications in English, teach her undergraduates in Finnish, and give public lectures in Swedish, but she cannot combine a set of different religious (and non-religious) affiliations, alternating Lutheran, Orthodox Jewish and atheist stances depending on the composition of her social environment. Cultural diversity makes for a variation of basic patterns of identification and orientation that may adopt discrete forms at the level of groups and of individuals. Yet, the connection between the collective and the individual element is more rigid in the realm of religion than in the realm of language. Even if our potential for mastering new languages has limits, as individuals we are able to familiarize ourselves with different communicative codes and to become proficient in several languages. If, as a not uncontroversial view of language holds, particular languages contribute to framing how we see things in particular ways, ${ }^{5}$ it is also true that by learning new languages we may acquire different standpoints from where to grasp the world, as Wilhelm von Humboldt (2003 [1836]: 327) put it two centuries ago. Our individual capability for coping with a multilingual repertoire would thereby make for a capability to act from varying linguistic standpoints that must remain without correspondence in the realm of religious attachments.

One may assume that attempts at working out an institutional approach towards linguistic diversity should benefit from the relative elasticity of our communicative dispositions and skills: the main strategy to adopt would consist in generalizing multilingual repertoires in a way that allows people to open linguistic gates and to secure linguistic ties. Unfortunately, however, such an approach does not turn multilingualism into some kind of magic formula that could be introduced uniformly and without further specifications to simultaneously pay tribute to diversity and avoid language conflict. Our potential to develop multilingual repertoires gives our linguistic identities an alterable and complementary character. At the same time, this very alterability also affects the relationship of 
what we perceive to be the key elements of gate-opening and tie-securing in connection with the status of particular languages. In the case of the Basque scholar, for instance, having the vernacular just as a language for feeling at home with relatives and friends is not enough. The great weight he assigns to tie-securing does not remain restricted to his private life, but impacts heavily on his professional activities as well. Thus, when it comes to the Basque case, the line between the 'proper' domains of tie-securing and gate-opening becomes blurred. To summarize: multilingualism entails the possibility of finding a balance between different languages; the balance, however, may well be more precarious than it appears to be at first sight, as the context-dependence and changeability of what we perceive as an option, and of what we perceive as a ligature in the domain of language, also makes for an inescapable moment of tension.

The perspective advocated here implies that the relationship between multilingualism and life chances must not be reduced to the instrumental dimensions of language repertoires. To the extent that our linguistic commitments tend to be closely intermingled with questions of selfcategorization and self-esteem, we must bring into focus the expressive dimension of language. ${ }^{6}$ Against this background, assessing the issue of linguistic diversity at the European level offers promising opportunities for developing a fresh perspective. Following the argumentation presented thus far, the point of departure for this assessment is the understanding that a normatively sound and sociologically informed institutional approach to language policy should foster multilingualism on the basis of respecting the equal dignity of people who belong to different language groups. It should create options, while maintaining ligatures. It should provide us with linguistic gates, while allowing us to cultivate our linguistic ties.

\section{Overview of the EU legal and policy framework on linguistic diversity and multilingualism}

The following overview assesses EU legal provisions and policies that aim at protecting linguistic diversity and enhancing the multilingual repertoires of European citizens. In which ways are the dimensions of tie-securing and gate-opening conceptualized in the Union's official discourse? Although EU policies may be of critical importance in terms of enhancing the multilingual repertoires and concomitant 'life chances' of European citizens, and in terms of contributing to the maintenance of particular linguistic identities, a systematic assessment of EU policy effectiveness in the national and/or local contexts is not, per se, the aim of this section. Rather, we are explicitly 
focusing on the EU official discourse that, by outlining the policy objectives, subscribes to a peculiar framework of normative and instrumental explanations for tie-securing and gate-opening language policy arrangements, which in the end, however, may appear to be inadequate to address the needs and interests of specific language groups. Simultaneously, it should be acknowledged that, although linguistic diversity remains entrenched as one of the key values of the European project, the EU holds relatively limited competences in this field. The principal responsibility for maintaining or enhancing linguistic diversity and multilingualism remains with the Member States. This creates a situation where concerns about linguistic diversity and cultural heritage at the supranational level often do not translate into parallel considerations of the intrinsic value of, and respect for, minority or regional languages at the level of the Member States. The role of the EU in this regard is rather to support and supplement the activities of the Member States aimed at preserving linguistic diversity. In the following discussion, we distinguish between three phases in the development of the EU approach to linguistic diversity and multilingualism which relate to the shifting nature of EU policy goals and the simultaneous evolution of the Member States' national interests and agendas on linguistic diversity.

\section{The foundations of the EEC/EU language regime}

With the establishment of the European Economic Community (EEC) in $1957^{7}$, the six founding Member States - France, Germany, Italy, Belgium, Luxembourg and the Netherlands - committed to upholding a linguistic regime which accorded the then four national languages of the EEC members (French, German, Italian and Dutch) an equal status. The text of the founding EEC Treaty was drawn up in all four languages and, as specified by its Article 248 (now Article 55 of the Lisbon Treaty), each of these versions was to be treated as 'equally authentic' ${ }^{8}$. The legal foundations for the language regime of the EEC were further laid down in the Council's Regulation No 1 of 15 April 1958, which states that '[t]he official languages and the working languages of the institutions of the Community shall be Dutch, French, German and Italian' (Article 1) and that 'regulations and other documents of general application shall be drafted in the four languages' (Article 4) (Council of the EEC, 1958: 385). It also provided for persons or Member States to choose their preferred language, out of the four official and working languages, in communication with the Community institutions (Article 2) (Council of the EEC, 1958: 385).

The latter developments could be regarded as the first phase in the construction of the EEC/EU approach to linguistic diversity which is characterized by the principle of political and linguistic 
equality between the Member States and the democratic imperative of overcoming linguistic barriers, enacted by provisions for multilingual communication with the citizens of the Member States. The formal principle of linguistic equality remained unchanged following several waves of enlargement and the concomitant growth in complexity of the language issue in the EEC/EU. The EEC Treaty was translated into each of the official languages of the newly acceding states. Likewise, the Council's Regulation No 1 has been modified to include the official languages of the new Member States, with the exception of Irish, which acquired full status of a working language of the EU institutions only in 2007. However, it remains questionable to what extent the formal endorsement of the equality of the national languages of the Member States represents a consistent commitment of the EU, as the internal communication within the institutions is typically carried out in a much narrower selection of the working languages - English, French and, to a much lesser extent, German ${ }^{9}$. The need to find a balance between economic efficiency and formal equality of the official languages, between practical considerations of effective communication and egalitarian values remains an unresolved dilemma for the EU, as will be shown further.

In addition, this brings into attention the ambiguous position, on the part of the EU, towards the use of regional and minority languages at EU level, which may or may not have a co-official status in all or part of the territory of the Member States. As of 2005, the Council authorized the limited use at EU level of 'languages other than the languages referred to in Council Regulation No 1 whose status is recognized by the Constitution of a Member State on all or part of its territory or the use of which as a national language is authorized by law'. The latter linguistic arrangements have to be requested and financed by the Member States' government. In practice, this has consequently affected the status of Catalan, Galician and Basque, whose speakers, as a result of an agreement between the EU and the Spanish government, may now address the European Parliament (EP) or the European Ombudsman and receive a reply in their mother-tongue. Thus, while the latter linguistic provisions may facilitate better integration of European citizens who happen to speak regional or minority languages, the competence to decide over language arrangements with regard to these languages still remains strictly embedded within the domain of the Member States. It could therefore be argued that the logic behind the latter linguistic provisions for the speakers of regional and minority languages is foremost aimed at ensuring effective communication of European citizens with EU institutions, whereas the value of their linguistic identities occurs as a secondary issue.

What becomes obvious, in this respect, is that the imperative of maintaining linguistic equality and protecting linguistic diversity in the EU is, first and foremost, designed to uphold the diverse 
linguistic identities of the Member States rather than those of its citizens. While this, quite unsurprisingly, given the limited competence of the EU in language policy, stems from the primacy of the decision-making at the Member State level, it consequently renders the insistence in the EU official discourse on the value of cultural and linguistic diversity limited in its ability to translate into effective policy measures that would guarantee equality of people's diverse linguistic identities and rights. As will be demonstrated further, the focus on the minority standards by the EU has not been able to bring about effective realignment in the hierarchy of the decision-making process in Europe in the field of cultural and linguistic diversity.

Securing linguistic ties: Minority standards and anti-discrimination provisions in the EU

The framework of minority standards, developed in cooperation with the Council of Europe $(\mathrm{CoE})$ and applied in the successive eastern enlargements of the EU, was another policy area in which the EU's attention to protection of, and respect for, internal linguistic diversity of the Member States has manifested. During the 1990s and early 2000s, the increased attention of the EU to minority protection, particularly in the candidate states of Central and Eastern Europe (CEE), was largely mirroring the developments of the political agenda of the Organization for Security and Cooperation in Europe (OSCE) and the $\mathrm{CoE}$ - namely, concerns over security and democratization in CEE. The Council of Europe's Framework Convention for the Protection of National Minorities has been the EU's main instrument for translating the minority criterion of political conditionality, as defined by the Copenhagen Council of 1993, into practice (Sasse, 2009: 20). Only the candidate countries of CEE were strongly encouraged to adopt it, causing concerns about the double standards for the 'new' EU Member States. This has been most eloquently illustrated by the fact that France has neither signed nor ratified the Framework Convention, whereas Belgium and Greece, for example, have signed, but not ratified it yet. In addition to that, although it is the first legally binding instrument aimed at the protection of national minorities, the Framework Convention has nevertheless left the Parties a considerable measure of discretion in implementing the principles of the Convention. This can be illustrated, for instance, by Article 14, paragraph 2, where the obligation to provide teaching of and instruction in a minority language was made dependent on the 'sufficient demand' and available resources, and further specified by the wording that the contracting States will seek to ensure this provision 'as far as possible'. As a result, minority rights, to a large extent, remain within the competence area of the Member States, particularly with regard to the 'old' Member States which are not exposed to the same level of pressure to comply as the 'new' candidate states seeking accession to the EU. 
The European Charter for Regional or Minority Languages is yet another instrument of the $\mathrm{CoE}$ which extends beyond the basic anti-discrimination measures, laid down in the European Convention on Human Rights, to guarantee positive protection and promotion of minority languages in education, the media, judicial and administrative settings, cultural activities as well as economic and social life ${ }^{10}$. Although it is generally agreed that the Charter constitutes the key legal frame of reference as regards minority language protection, we should take into account that each of the contracting States has a rather wide range of discretion on the implementation of the Charter's provisions: As outlined in Article 2, each party can select to apply at least thirty-five paragraphs or subparagraphs from the provisions specified in Part III of the Charter, which vary greatly in their stringency, as well as choose to apply a different selection of paragraphs or subparagraphs to a particular minority or regional language. As a result, the scope of protection and promotion can vary across different minority or regional languages, identified by the contracting States as spoken within their frontiers. Another crucial feature of the Charter is that it primarily aims to protect those minority or regional languages which have some sort of territorial base - in other words, they are spoken in a particular geographical area - and are historical languages or 'traditionally used' in that area, which, in turn, excludes the languages of immigrants from the definition. As a consequence, a very limited number of linguistic communities may be accorded recognition and language protection, disregarding those which do not represent 'traditional', historically entrenched, standardized languages ${ }^{11}$.

In addition to that, minority standards have been extensively and even predominantly defined within the EU by the anti-discrimination legal framework, with the aim of guaranteeing equal opportunities for persons belonging to national minorities and to overcome social exclusion. The adoption of antidiscrimination legislation has been made integral to both political and acquis (Race Equality Directive of 2000) conditionality (Schwellnus, 2009: 34), applied to the candidate countries of CEE. Besides the Race Equality Directive, the EU enacted the Employment Framework Directive which prevents discrimination at work on grounds of religion, belief, disability, age and sexual orientation. Both candidate states and Member States were obliged to transpose the Directives into their national legislation, limiting the concerns about the double standards for the 'old' and 'new' EU Member States. The Charter of Fundamental Rights of the European Union, which acquired full legal effect upon the entry into force of the Treaty of Lisbon on 1 December 2009, has further strengthened the EU's legal framework on anti-discrimination, which can now be said to encompass a non- 
exhaustive list of grounds on which discrimination is prohibited, thus addressing complex structures of diversity, including affiliation with a national minority or language.

The development of the minority rights regimes and non-discrimination provisions, against the background of the enlargements - in particular, the Eastern enlargements of 2004 and 2007 represents what could be regarded as a second phase in the process of construction of the Union's approach to linguistic diversity. Its distinguishing feature is represented by a move towards the conceptualization of linguistic diversity in terms of its language-as-ligature dimension, wherein the protection of the diverse identities of the Member States' citizens emerges as a particularly relevant concern for the EU, even if this has been mainly dictated by the international security imperatives. However, the lack of a coherent and systematic approach to the protection of minority rights across different national contexts of the Member States remains an acute problem for the EU and is, to a large extent, determined by peculiar interests and approaches to linguistic diversity of the Member States. Therefore, the tie-securing aspects of the official EU discourse, expressed via affirmations of linguistic rights of minorities, stumble against the national agendas of the Member States, with France, for instance, being an exceptionally good illustration of the failure of the EU to enforce positive minority rights and recognition of the equal dignity of minority languages ${ }^{12}$. Even in the 'new' Member States of CEE, the degree of attention that the EU gave to different minority groups in the series of the pre-accession monitoring reports was strongly affected by the diverging levels of 'sensitivity' of certain minority issues. Thus, the minority rights of the non-territorialized Roma population in $\mathrm{CEE}$, as a less politically sensitive concern, received much more attention from the EU than, for instance, a politically controversial situation of the Macedonians in Bulgaria or the Hungarians in Slovakia (Sasse, 2009: 22). Such inconsistencies between the EU discourse and the de facto realities in the national contexts are telling of the limited content of the EU motto 'united in diversity': it crucially demonstrates that the EU concern with minority language rights does not embody a principled commitment to uphold the equal dignity of the citizens' diverse linguistic identities. Rather, it is reducible to a vague normative rhetoric of respect, subordinated to, and controlled by, the Member States' agendas.

Intrinsic value or utility? Mixed rationale of the EU multilingualism and language learning policy

The Union's commitment to promoting and protecting linguistic diversity has simultaneously manifested in the multilingualism and language learning policy, which has been steadily gaining prominence over the past two decades. The field of education, in particular, has been affected by the 
increased attention to the benefits of language learning. In 1989, the EEC initiated the Lingua program, aimed at providing financial support for initiatives which allow students and language teachers to learn foreign languages in other Member States. Socrates, Erasmus, Leonardo da Vinci and the new Lifelong learning programs, respectively, have been promoting language learning and multilingualism through student exchanges in secondary and higher education as well as vocational training.

With the advent of the Maastricht Treaty in 1992, the Union has officially endorsed its role in promoting language learning in the field of education, as stated in Article 126 (now Article 165): 'Community action shall be aimed at developing the European dimension in education, particularly through the teaching and dissemination of the languages of the Member States', while 'fully respecting the responsibility of the Member States for the content of teaching and the organization of education systems and their cultural and linguistic diversity'. The inherent tension in the wording of Article 126 once again illustrates the limited competence of the EU to take a more pro-active course of policy measures in protecting and promoting linguistic diversity.

As to the extent of linguistic diversity that has been promoted by these educational programs, it was quite obvious that the regional and minority languages were not among the targeted languages and that the official languages of the Member States, mentioned in the Council Regulation No 1, would be the primary beneficiaries. Hence, when the Council Resolution of 31 March 1995 on improving and diversifying language learning and teaching within the education systems of the European Union invited Member States to 'take steps to encourage diversification in the languages taught in the Member States, giving pupils [...] the opportunity to become competent in several languages of the European Union' (Council of the European Union, 1995: 1), it first and foremost encouraged learning of less widely used and taught official languages of the EU, therefore, excluding regional and minority languages from the definition.

Moreover, the EU official discourse surrounding the establishment of the European Year of Languages 2001 exposed the mixed rationale supporting the initiatives for promotion of multilingualism and language learning. While the Decision of the EP and the Council establishing the European Year of Languages 2001 indicates that it is still important 'to raise awareness of the richness of linguistic and cultural diversity within the European Union and the value in terms of civilization and culture embodied therein, acknowledging the principle that all languages must be recognized to have equal cultural value and dignity' (European Parliament and Council of the 
European Union, 2000: 3), it likewise becomes crucial 'to bring to the notice of the widest possible public advantages of competencies in several languages, as a key element in the personal and professional development of individuals [...] and in enhancing the economic and social potential of enterprise and society as a whole' (European Parliament and Council of the European Union, 2000: 3). The conflation of the non-pecuniary and marketable value of diversity, of cultural and economic incentives as the basis for promotion of cultural and linguistic diversity that becomes manifest here is a good illustration of the tensions to which the EU discourse on diversity is typically prone. On the one hand, the language-as-tie dimension is emphasized via an endorsement of the equal cultural value and dignity of all languages; on the other hand, the economic potential of turning cultural and linguistic diversity into an asset is brought up as an equally pertinent aspect of diversity management, thereby conceptualizing cultural and linguistic diversity primarily in terms of its strategic gate-opening qualities in the realm of competitiveness.

The dominance of economic imperatives underlying the Union's commitment to the promotion and protection of linguistic diversity and multilingualism re-emerged once again in 2003, when the Commission, responding to the Council's request for concrete policy actions to promote linguistic diversity and language learning (Council of the European Union, 2002), issued an Action Plan for the period of 2004-2006 (Commission of the European Communities, 2003). Although the introduction of the Action Plan begins by stressing the contribution of language learning to intercultural dialogue and effective communication in the increasingly diverse EU, it soon moves on to highlighting the links between language and entrepreneurial skills of EU citizens in a competitive knowledge-based economy, which the EU aspires to become, particularly with regard to the economic goals of the Lisbon strategy.

In 2005, 'A New Framework Strategy for Multilingualism' (Commission of the European Communities, 2005) was issued by the European Commission that presents an attempt at outlining a coherent EU policy approach on multilingualism and linguistic diversity. The 2005 Communication reaffirms the commitment of the Commission to multilingualism and sets out the strategy for promoting multilingualism with three primary policy priorities: 1) encouragement of language learning and linguistic diversity in society; 2) promotion of a healthy multilingual economy; and 3) equality of access for EU citizens to EU legislation, procedures and information in all official EU languages. The key imperatives become the growth of individual multilingualism and turning linguistic diversity within the EU into an economic asset for the development of a dynamic knowledge-based economy which would be able to successfully compete in the global market. As a 
result, much emphasis is given to language learning as a gateway for wider employment opportunities and social integration, economic growth and innovation, thereby contributing to the objectives of the Lisbon strategy and the renewed 'Europe 2020' strategy for growth ${ }^{13}$. The longstanding discursive insistence on the cultural value of diversity in the EU's official discourse gets outweighed by a utility-based approach which shifts the importance to the gate-opening potential of linguistic diversity and multilingualism and is subsequently translated into policy by an increased focus on effective language learning and teaching from an early age as the key policy measure.

The subsequent Commission's Communication of 2008 - 'Multilingualism: an asset for Europe and a shared commitment' - was structured along more or less the same policy objectives (Commission of the European Communities, 2008). Effective language teaching and language learning of a range of languages from an early age are endorsed with a view of how this, in turn, contributes to competitiveness of the European businesses and EU economy, employability, creativity and innovation, social cohesion and effective communication in local diverse environments, at the supranational EU level as well as in the Union's external relations. Likewise, the tension between the tie-securing and gate-opening dimensions in the approach adopted by the EU are left unresolved, if not made even more acute, as the following passage from the 2008 Communication demonstrates. While it is initially underlined that 'each of the many national, regional, minority and migrant languages spoken in Europe adds a facet to our common cultural background' (Commission of the European Communities, 2008: 5), a section titled 'Valuing all languages' soon offers more insight into what is that the EU values: '[i]n the current context of increased mobility and migration, mastering the national language(s) is fundamental to integrating and playing active role in society', while the languages of migrants and minorities should be valued in society as 'untapped linguistic resources' (Commission of the European Communities, 2008: 6). In a nutshell, the approach to linguistic diversity, endorsed by the Commission, shifts the centre of gravity towards an understanding of the value of a language as a gate-opening, option-providing medium for professional achievement, integration, economic growth and prosperity.

In this context, it is interesting to observe that the EP holds a somewhat divergent position vis-à-vis the multilingualism and language learning policy. From the early 1980s, the EP has consistently endorsed a language policy course which gives more importance to the protection and promotion of lesser-used languages, particularly regional and minority languages. With regard to the two aforementioned Commission's Communications, the EP has issued two resolutions (European Parliament, 2006; European Parliament, 2010). The first of these was preceded by a draft report, 
which included an explanatory statement offering a more straightforward criticism of the Commission's multilingualism policy (Joan i Marí, 2006) ${ }^{14}$. Among the main issues that were brought up in this statement was the ambiguous position on the part of the Commission towards non-official languages of the EU as well as lesser-used languages more generally. As a result, the need to make all European languages official, not just the national languages of the Member States, was particularly stressed. The funding mechanisms of the Commission's multilingualism policy were further identified as excluding the smaller languages and minoritized language communities which have to stand in direct competition for funding allocations with bigger languages and, thus, are marginalized, lacking funds which would be earmarked for such smaller languages specifically. Hence, the statement called for 'coherent, meaningful EU language policy and legislation' which would enshrine language rights in order to ensure that all European languages are protected and are given the social linguistic space in which to thrive. This position was likewise represented in the two resolutions of the EP on Commission's Communications: the 2006 resolution highlighted that 'proposals for multilingualism should not be limited to the main official/Member State languages' (European Parliament, 2006: 209), whereas the 2009 resolution reminded that 'the importance of multilingualism is not confined to economic and social aspects and that attention must also be paid to cultural and scientific creation and transmission', as well as to the role of languages in shaping one's identity (European Parliament, 2010: 61).

The institutional split with regard to the rationales underlying the concern with linguistic diversity emerged in 1997 in the form of a court case between the European Parliament and the Council before the European Court of Justice, when the two institutions disagreed on what should be the basis - economic or cultural incentives - for adopting a multiannual program for the promotion of linguistic diversity in the EU. The decision of the Council (Council of the European Union, 1996) to establish such a program solely on the basis of Article 130 of the EU Treaty (now Article 173), in which the competitiveness of the Community's industry is identified as a key objective, clashed with the Parliament's proposal that the program should also be based on Article 128 (now Article 167), which underlines that the Community has to 'contribute to the flowering of the cultures of the Member States, while respecting their national and regional diversity'. A weighty factor facilitating the conflict between the two EU institutions in this case was the fact that the Council, when basing the program solely on Article 130, would not have needed a formal approval or a co-decision of the Parliament in order to adopt the measures of the program. However, the European Court of Justice, after having reviewed the case, concluded that '[1]anguage', in the context of the Council's Decision and the proposed program, is seen not as an element of cultural heritage but rather as an object or 
instrument of economic activity' and that 'the object of the program, namely the promotion of linguistic diversity, is seen as an element of an essentially economic nature and incidentally as a vehicle for or element of culture as such' (European Court of Justice, 1999). This ruling, consequently, could be seen as marginalizing the Parliament's efforts to shift 'the centre of gravity' towards cultural aspects of linguistic diversity and reducing its capacity to influence the contents of the policy regulating linguistic diversity in the EU.

The diverging perspectives of the EP, the Commission and the Council on the normative basis and policy measures to be undertaken in the EU's policy framework on linguistic diversity and multilingualism are a consequence of an array of concomitant factors. Firstly, as the legislative body of the Union, the EP has to ensure accessibility and transparency of its work and, therefore, is more apt to implement the principle of linguistic equality in its internal workings which means that all the parliamentary documents are translated into all the official languages and every Member of the European Parliament (MEP) has the right to speak in any of the official languages of the EU. Furthermore, as illustrated by the court case between the Council and the EP, the insistence of the latter on the cultural aspects of diversity may represent a power struggle between the two institutions. Lastly, some MEPs have been more proactive in promoting greater recognition of regional and minority languages, for instance, by forming the Intergroup for Traditional Minorities, National Communities and Languages in 2010 (with currently 41 members).

Against this background, the recent focus on multilingualism and language learning policy represents a shift towards the language-as-gate dimension, conceived of solely in terms of economic growth and integration. The EU's discourse on linguistic diversity, although still undergirded by humanistic value-based argumentation, increasingly gravitates towards the utility-based economic rationalization in which the value of linguistic diversity is instrumentalized, pinning it to a range of economic and social objectives, such as competitiveness of the EU economy, mobility and professional advantages for individuals, innovation and social cohesion. The tension that lies therein is symptomatic of the concurrent EU struggle to strike a balance between the two normative poles assigned to diversity, as laid down in Article I-3 of the Lisbon Treaty - the promotion of economic, social and territorial cohesion and the respect for the Union's rich cultural and linguistic diversity. Once the value of linguistic diversity becomes increasingly measured against the standard of the utility of citizens' multilingual repertoires, based on a simplified understanding of the value of a language, the foundations of the EU's long-standing commitment to the protection of cultural and linguistic diversity become mere lip-service to the principle of equality of dignity and value of all 
European languages - whether these would be national, minority, regional or migrant languages. While the market-driven focus on a healthy multilingual economy is understandably predicated by the higher competences of the Commission in this field, it constrains the recognition of linguistic diversity at EU level to mere symbolic politics, leaving the current EU language regime devoid of a balanced and national/local context-sensitive set of tie-securing and gate-opening policy arrangements. Such inconsistencies in the EU discourse not only reveal the prolonged avoidance of a debate on how to regulate linguistic diversity and multilingualism in the EU - it exposes the ineffectiveness of the present power-sharing arrangements between the Member State governments and the EU. Hence, the EU is facing the challenge of finding a way to reconcile the normative underpinnings of its official motto 'united in diversity' with the actual language policies in the Member States, which often fail to provide appropriate tie-securing and gate-opening opportunities for European citizens and, even more so, the means to challenge the existing national language regimes. For a more congruent EU language policy framework to be developed the EU institutions need to reconsider the normative discordances that permeate their approach to linguistic diversity as well as to tackle the issue of persisting inequalities in the dignity and value attached to the languages spoken within the EU (Kraus, 2011: 30-31).

At the same time, it seems clear that the endeavour will hardly be successful without the commitment of the Member States. In this respect, it must be stressed that the dynamic of Europeanization reaches way beyond the limits subject to the immediate control of EU institutions. One of the dynamic's main effects is precisely that the European policy dimension has been internalized by institutional actors who operate at national or regional levels at which the EU does not hold relevant competences. The Bologna process, with its manifold linguistic aspects, offers a clear-cut example of this internalization process: education is not an area subject to EU regulations; still, not only EU members, but even non-members, such as Norway or Switzerland, have made major efforts to introduce common European standards and converging curricula in the realm of higher education. Thus far, Bologna has made an important contribution to reinforcing the role of English as the de facto European lingua franca, as it has significantly increased the presence of English in the teaching plans of non-English speaking universities all over Europe, with the purpose of facilitating the transnational mobility of students. In this respect, as in many others, Europeanization does not seem to be entailing more linguistic diversity, but rather the opposite, namely the establishment of English as the language of trans-European communication. This may or may not be in line with the policy preferences of key players in the EU and in the Member States. However, it does not add credibility to a policy framework built up along the rationale of 
safeguarding linguistic diversity, as even the status of formerly dominant languages is increasingly challenged in a context where Europeanization is concomitant with Anglicization.

\section{Conclusion}

As was pointed out above, the initial phase in the development of the EEC/EU approach to linguistic diversity was marked by the formal appraisal of the equality of linguistic identities of the Member States as well as the imperatives of effective communication between the European institutions and the citizens of the Member States. While these principles remained embedded in the official language regime of the EEC/EU with each successive enlargement, the accession of the new Member States of CEE in 2004 and 2007 brought about an emphasis on the protection of linguistic identities through the required compliance with an anti-discrimination framework and minority provisions. The latest developments in the EU's approach to linguistic diversity and multilingualism imply a conflation of two logics of value - non-pecuniary and marketable - that prioritizes the latter in terms of concrete policy actions.

In consequence, the EU discourse on the inherent value of cultural and linguistic diversity, as a core value of the European project, is, on the one hand, at risk of being subordinated to the over-arching economic goals of growth, competitiveness and market integration. At the same time, the remaining hierarchies of recognition and entitlement attributed to different language groups within the EU are symptomatic of the lack of normative coherence and principled commitment towards respecting people's diverse linguistic identities. Paradoxically, 'unity in diversity' becomes de facto a unity in segmented diversity and status inequality, modeled according to an identity politics of the Member State governments, where the main beneficiaries of the EU commitment to defending linguistic diversity remain the official languages of the Member States.

It remains to be seen whether European English will trigger a transnational debate that could ultimately contribute to the creation of a more consistent language policy framework. This would not lack a certain irony, as there are many good reasons for perceiving English as a threat to cultural diversity in Europe (Phillipson, 2003). Nonetheless, at least from the minority perspective, the spread of English through Europeanization might entail an unexpected positive by-effect: to the extent that it contributes to a substantial increase of a multilingual repertoire among the bulk of European citizens, it also bears the potential of transforming the relationship between layers of 
linguistic diversity. To end with an optimistic note, we should not rule out that the emergence of an English-speaking 'super-majority', which includes both linguistic majorities and minorities in Europe, increases the awareness of those who belong to majorities - majorities that, it should be noted, are on the way to becoming 'former' linguistic majorities in relation to English - for issues of linguistic equality, for the concerns of the speakers of 'smaller' languages, and for the persisting need of finding a fair balance between 'tie-securing' and 'gate-opening' language policies in a context of diversity.

\section{Notes}

${ }^{1}$ Part of the work on this paper has been elaborated in the context of Eurosphere, an integrated project funded by the European Union's 6th Framework Programme (CIT4-CT-2006-028504). Peter A. Kraus' work reported on in this publication has also been supported by the European Science Foundation (ESF), in the framework of the Research Networking Programme RECODE.

${ }^{2}$ René Schiering, quoted in Spiegel Online, 28 Aug 2011.

${ }^{3}$ In this respect, it is worth quoting the Finnish-American historian John Wuorinen (1931: 53). In his remarkable wording, Finland's elites, largely a Swedish-speaking group in the 19th century, had to 'adopt Finnish as their mother tongue' to create the conditions for the Finns to 'become a fully united nation'. By doing so, they substantially contributed to inverting the situation of subordination the Finnish language had been exposed to and to establishing a framework that protected Finnish from becoming an endangered vernacular.

${ }^{4}$ See, for instance, the account Szeverényi and Wagner-Nagy (2011) give of the situation of the Nganasans, a small Finno-Ugric group whose territory is on the Taymyr Peninsula, in the West Siberian North. The dying of their language goes hand in hand with a waning of group identity that has not entailed, however, the provision of new options for group members.

${ }^{5}$ Deutscher (2010) presents a recent re-statement of this perspective.

${ }^{6}$ See Kraus (2008: 78-83) for an elaboration of this point.

${ }^{7}$ The EEC, renamed into European Community (EC), became the principal component of the European Union, established by the Treaty of Maastricht in 1992.

${ }^{8}$ Article 55 of the Lisbon Treaty also encourages the Member States to translate the Treaties into other languages which hold an official status in part or all of the Member State's territory.

${ }^{9}$ Another illustration of the limited equality of the official languages comes from a series of court cases Kik v. Office for Harmonisation in the Internal Market (OHIM). While it is possible to submit a trademark application to OHIM in any of the official languages of the EU, only 5 languages - 
English, French, German, Italian and Spanish - are recognized as official OHIM languages, and only these are in consequence used in handling the application and communication with an applicant. Ms. Kik claimed that OHIM, by excluding Dutch from its set of official languages, undermined the principle of linguistic equality of the Member States, as laid out in the Council Regulation No 1. The European Court of Justice concluded in its ruling that the language regime of OHIM was justifiable due to the economic and voluntary nature of the institution and the need to find a balance in terms of the costs of proceedings. For a detailed analysis of the Kik case, see Richard L. Creech (2005).

${ }^{10}$ Out of the 27 EU Member States, 16 have both signed and ratified the Charter, 3 have signed, but not yet ratified the Charter, whereas 8 have neither signed nor ratified it. In the context of CEE, Bulgaria, Estonia, Latvia and Lithuania have neither signed nor ratified the Charter, in contrast with Hungary, Czech Republic, Poland, Slovenia, Slovakia and Romania, which both signed and ratified it within the period of 1998-2009.

${ }^{11}$ The currently existing standards for minority and regional language protection appear problematic if we consider the observation of Michael Silverstein (2010) that the Enlightenment sociopolitical theories and their normative ascriptions of language communities offer recognition only to those linguistic communities that are either polities or polities-in-potentia (stateless nations). These ascriptions rest on a premise that political like-mindedness can only be achieved through a shared standardized language medium and, in effect, ignore the linguistic identities of complex, plurilingual, pluricultural communities in which people actually live.

${ }^{12}$ France, officially, does not recognize any minority groups on its territory. Accordingly, it has not signed the Framework Convention for the Protection of National Minorities, whereas it has signed, but failed to subsequently ratify the European Charter for Regional or Minority Languages.

${ }^{13}$ See, for instance, Heller (2003) who discusses a similar shift in francophone Canada where the emphasis on the value of language as an identity marker is replaced by the discourse about the 'added value' of linguistic skills in the job market.

${ }^{14}$ The draft report and the accompanying statement were a personal initiative of the Catalan MEP Bernat Joan i Marí and were adopted in the EP by 537 votes in favor to 50 against and 59 abstentions.

\section{References}


Commission of the European Communities (2003) Communication from the Commission to the Council, the European Parliament, the Economic and Social Committee and the Committee of the Regions, Promoting Language Learning and Linguistic Diversity: An Action Plan 2004 -2006, COM (2003) 449.

Commission of the European Communities (2005) Communication from the Commission to the Council, the European Parliament, the European Economic and Social Committee and the Committee of the Regions, A New Framework Strategy for Multilingualism, COM (2005) 596 final.

Commission of the European Communities (2008) Communication from the Commission to the Council, the European Parliament, the European Economic and Social Committee and the Committee of the Regions "Multilingualism: an asset for Europe and a shared commitment", COM (2008) 566 final.

Council of the European Economic Community (1958) Regulation No 1 determining the languages to be used by the European Economic Community. Official Journal of the European Communities, 017, 385-386.

Council of the European Union (1995) Resolution of 31 March 1995 on improving and diversifying language learning and teaching within the education systems of the European Union. Official Journal of the European Communities, C 207, Volume 38, 1-5.

Council of the European Union (1996) Decision of 21 November 1996 on the adoption of a multiannual programme to promote the linguistic diversity of the Community in the information society (96/664/EC). Official Journal of the European Communities, L 306, Volume 39, 40-48.

Council of the European Union (2002) Resolution of 14 February 2002 on the promotion of linguistic diversity and language learning in the framework of the implementation of the objectives of the European Year of Languages 2001. Official Journal of the European Communities, C 50, Volume 45, 1-3.

Creech RL (2005) Law and Language in the European Union. The Paradox of a Babel "United in Diversity”. Groningen: Europa Law Publishing. 
Dahrendorf R (1979) Life Chances: Approaches to Social and Political Theory. Chicago: University of Chicago Press.

Deutscher G (2010) Through the Language Glass: How Words Colour Your World. London: William Heinemann.

European Court of Justice (1999) Case C-42/97, Parliament vs. Council, Judgment of the Court on the Council Decision 96/664/EC.

European Parliament and the Council of the European Union (2000) Decision No 1934/2000/EC of the European Parliament and of the Council of 17 July 2000 on the European Year of Languages 2001. Official Journal of the European Communities, L 232, Volume 43, 1-5.

European Parliament (2006) Resolution on a new framework strategy for multilingualism (2006/2083(INI)). Official Journal of the European Union, C 314 E, Volume 49, 207-210.

European Parliament (2010) Resolution of 24 March 2009 on Multilingualism: an asset for Europe and a shared commitment (2008/2225(INI)). Official Journal of the European Union, C 117 E/10, Volume 53, 59-64.

Heller M (2003) Globalization, the new economy, and the commodification of language and identity. Journal of Sociolinguistics 7(4): 473-492.

Joan i Marí B (2006) Report on a new framework strategy for multilingualism (2006/2083(INI)), European Parliament, Committee on Culture and Education.

Kraus PA (2008) A Union of Diversity: Language, Identity and Polity-Building in Europe. Cambridge: Cambridge University Press.

Kraus PA (2011) The language issue and political legitimation in the European Union: Neither unity nor diversity? In: Kjær AL and Adamo S (eds) Linguistic Diversity and European Democracy. Farnham: Ashgate, pp. 17-33.

Phillipson R (2003) English Only Europe? Challenging Language Policy. London: Routledge. 
Sasse G (2009) Tracing the construction and effects of EU conditionality. In: Rechel B (ed) Minority Rights in Central and Eastern Europe. London and New York: Routledge, pp. 17-31.

Schwellnus G (2009) Anti-discrimination legislation. In: Rechel B (ed) Minority Rights in Central and Eastern Europe. London and New York: Routledge, pp. 32-45.

Silverstein M (2010) Society, polity, and language community: An Enlightenment trinity in anthropological perspective. Journal of Language and Politics 9 (3): 339-363.

Spiegel Online (2011) 1000 Fragen: Wie sterben Sprachen? Available at: www.spiegel.de/schulspiegel/wissen/0,1518,777771,00.html (Accessed 29 Aug 2011).

Szeverényi S and Wagner-Nagy B (2011) Visiting the Nganasans in Ust-Avam. In: Grünthal R and Kovács M (eds), Ethnic and Linguistic Context of Identity: Finno-Ugric Minorities. Helsinki: University of Helsinki/Finno-Ugrian Society, pp. 385-404.

von Humboldt W (2003 [1836]) Über die Verschiedenheit des menschlichen Sprachbaues und ihren Einfluß auf die geistige Entwicklung des Menschengeschlechts. Über die Sprache. Wiesbaden: Fourier.

Weiler JHH (1999) The Constitution of Europe. Cambridge: Cambridge University Press.

Wuorinen J (1931) Nationalism in Modern Finland. New York: Columbia University Press. 